Current Science International

EISSN:2706-7920 ISSN: 2077-4435

DOI: $10.36632 / \mathrm{csi} / 2019.8 .4 .16$
Volume : 08 | Issue : 04| Oct.- Dec. | 2019

Pages: 764-775

\title{
Antitumor and Antimicrobial activities of pomegranate (Punica granatum) dried powder peel in vitro
}

\author{
Asmaa M. Moghazy \\ Hormonal Evaluation Department, National Organization for Drug Control and Research. \\ (NODCAR). Giza, Egypt. E-mail: asmaamoghazy@hotmail.com
}

Maie S. Khader

Medicinal Plant Department, National Organization for Drug Control and Research. (NODCAR). Giza,Egypt.E-mail:mselmym@yahoo.com

\author{
Neveen Saleh \\ Microbiology Department, National Organization for Drug Control and Research. (NODCAR). Giza, \\ Egypt. E-mail:neveensaleh0@gmil.com
}

Received: 25 Sept. 2019 / Accepted 20 Nov. 2019 / Publication date: 10 Dec. 2019

\begin{abstract}
Background: The pomegranate fruit possesses therapeutically important constituents that gained significant popularity in the treatment of many diseases. Therefore, this study was carried out to investigate the phytochemical compounds of aqueous extract of pomegranate peel (PPE) along with its antimicrobial and antitumor effect on Colorectal (Caco-2) and Colon (HCT-116) cancer cell lines.

Method: Aqueous extract of Pomegranate peel was analyzed by HPLC technique. Furthermore, antimicrobial activity was investigating against Gram-positive, Gram-negative and fungi. Likewise, antitumor activity was tested in vitro on the human cell line Colorectal (Caco-2), and Colon (HCT116). The cytotoxicity was determined by using MTT assay. Cell cycle analysis, apoptosis, preapoptotic and apoptotic gene were analyzed by using Real-Time PCR. While catalase and hydrogen peroxide $\left(\mathrm{H}_{2} \mathrm{O}_{2}\right)$ were determined by using ELIZA Kits. Result: According to the obtained data, PPE extract contain polyphenolic compounds among which protocatechuic acid, p-hydroxybenzoic acid, and rutin showing the most predominant ones. Besides, PPE has antibacterial activity against Grampositive bacteria and anti-candida activity. Furthermore, PPE was cytotoxic to cancer cells in a concentration and cell type-dependent manner, where the Caco-2 cells were more sensitive to the PPE extract than HCT-116. Where $\mathrm{IC}_{50}$ of Caco- and HCT-116 are 1434 and $2257 \mu \mathrm{g} / \mathrm{ml}$ respectively. Additionally, the anticancer activity was secure via the up/downregulation of the pro-apoptotic gene (Caspase-3 and p53), both genes expression was cell type-dependent as well. While anti-apoptotic gene Bcl-2 showed a significant decrease $(\mathrm{P}<0.05)$. Also, the apoptotic potential of PPE was confirmed via the arresting of cells in the G2/M phase and elevated apoptotic cell \% in the pre-G1 phase. Data obtained also, increasing the level of $\mathrm{H}_{2} \mathrm{O}_{2}$ and decreasing catalase activity.

Conclusion: PPE has an anti-proliferative potential against Caco-2 and HCT-116 cancer cells through the induction of apoptosis. Besides, it has antimicrobial activity against Gram-positive bacteria.
\end{abstract}

Keywords: PPE, Caco-2, HCT-116, Caspase3, P53, Bc12, cell cycle, Antimicrobial

\section{Introduction}

Pomegranate belongs to the family Punicaceae. It is categorized under medicinal fruits recommended by Prophet Muhammad (PBUH). According to Al-Qur'an, pomegranate grows in the gardens of paradise and it is mentioned three times in the Al-Qur'an as an example of God's good creation. Pomegranate (Punica granatum L) cultivate in most countries of the Middle East, Mediterranean Sea, USA, and South Africa (Fawole et al., 2012). The pomegranate fruit possesses therapeutically important constituents, varying slightly in different parts of the fruit. Fruit of pomegranate consists of the outer peel which encloses inner seeds and arils.

The peel was used traditionally for treatment of ulcer and inflammation, and it has been showed antioxidant and bacterial activities (Rebogile et al., 2016; Sreerkumar et al., 2014). Several studies

Corresponding Author: Asmaa M. Moghazy, Hormonal Evaluation Department, National Organization for Drug Control and Research. (NODCAR). Giza, Egypt.

E-mail: asmaamoghazy@hotmail.com 
have demonstrated that the pomegranate peel is a good source of bioactive compounds such as catechin, ellagitannins, epicatechin, rutin, and many others. Such bioactive compounds are responsible for many biological activities such as antimicrobial, antioxidant, antiinflamatory (Glazer et al., 2012; Fawole et al., 2015). Additionally, other studies have shown the therapeutic effect of pomegranate fruit, juice, and peel for treatment of lung cancer, esophagus, cardiovascular disorders and breast cancer. It has free radical scavenging activities which mostly related to its phytochemical components (Abdollahzadeh et al., 2011; Qabaha, 2013). Besides, many studies have shown that pomegranate constituents can efficiently affect multiple signaling pathways involved in inflammation, cellular transformation, hyper-proliferation, angiogenesis, initiation of tumorigenesis, and eventually suppressing the final steps of tumorigenesis and metastasis (Khan et al., 2007; Faria, and Calhau, 2011).

The aim of these studies was designed to inspect phytochemical constituents of aqueous extract of pomegranate peel, antimicrobial and antitumor activities of PPE on Caco-2 and HCT-116 cell lines.

\section{Cell Death Pathways}

There are two types of programmed cell death which decide the fate of cells of malignant neoplasms which are apoptosis and necrosis. They are distinguished by their morphological differences. Apoptosis, an active, gene-regulated form of cell death, is the major type of cell death that is characterized by specific morphological and biochemical changes of dying cells. The morphological changes include cell shrinkage, nuclear condensation and fragmentation, membrane blebbing and loss of adhesion to neighbors or extracellular matrix while biochemical changes include chromosomal DNA cleavage into inter nucleosome fragments (McIlwain et al., 2013). On the other hand, necrosis is considered as accidental cell death, a random, uncontrolled process that caused profound effects on malignant cells. According to Ouyang et al. (2012), necrosis usually involves cell swelling, organelle dysfunction, and cell lysis. Necrosis also disrupts the integrity of the cells membrane which caused the release of intracellular materials, leading to an inflammatory response by immune cells. Apoptosis, a preferential way of elimination of damaged cells is regulated and controlled by a group of endoproteases known as caspases. Caspases play an important role in maintaining homeostasis by regulating cell death and inflammation. Caspases have been broadly categorized by their known functions in apoptosis [caspase-3, -6, -7, -8 and -9 in mammals] and in inflammation [caspase-1, $-4,-5$ and -12 in humans] (McIlwain et al., 2013). Initially, caspases are produced as inactive monomeric procaspases which require dimerization and cleavage for activation. There are two types of caspases which are initiator [caspases-8 and -9] and executioner caspases [caspases-3, -6 and -7]. In apoptosis, executioner caspases are activated by initiator caspases. Various apoptotic path-ways exist and most apoptotic programs fall into either extrinsic (death receptormediated) or intrinsic (mitochondria-mediated) pathway. The extrinsic apoptotic pathway is activated at the cell surface. The binding of pro-apoptotic ligands to the respective plasma membrane-localized receptors causes the monomeric pro-caspase- 8 to be recruited to the death-inducing signaling complex [DISC] (McIlwain et al., 2013) which then results in dimerization and activation. There are two outcomes resulted from the death receptor-mediated activation of caspase- 8 which depends on the cell types. In type I cells, apoptosis is initiated directly by cleaving and activating the executioner caspases [caspase-3) whereas, in type II cells, caspase- 8 must first activate the intrinsic apoptotic pathway to induce cell death.

\section{Materials and Methods}

\section{Reagent and Media:}

Fresh pomegranate fruits were collected from the local market at the Giza government, during September. Muller-Hinton agar (Difco, USA); Sabaurod Dextrose Agar (SDA), Oxoid, USA; RPMI1640 medium Trypsin $0.25 \%$, fetal calf serum (GIBCO, USA), ethylene diamine tetra-acetic acid (EDTA), methanol and ethanol were purchased from Sigma Aldrich-USA.

\section{Preparation of Pomegranate Peel Aqueous Extract (PPE):}

Fresh pomegranate fruits were peeled manually and the collected peels were then rinsed with distilled water. Peels were further cut into small pieces and dried at $50-60^{\circ} \mathrm{C}$ in a hot air oven for 
$24 \mathrm{hrs}$ and ground to a coarse powder using a grinder. Dried pomegranate peel was used to make aqueous extracts. Powder $(50 \mathrm{gm})$ of the dried peels were extracted with $250 \mathrm{ml}$ boiled distilled water at room temperature for $1 \mathrm{hrs}$. The PPE was concentrated by lyophilization using a freeze dryer (BUCHI Lyovapor L-200). The dried lyophilized powder was kept in a sealed glass container at $-5^{\circ} \mathrm{C}$ in dark until use. The total yield of aqueous extract was 4\%. Phytochemical constituents of aqueous extract of pomegranate peel (PPE) were carried out on an Agilent Technologies HPLC 1100 liquid chromatography according to Kim et al., 2006.

\section{Bacterial Strains:}

Reference microorganisms used in this study were purchased from American Type Culture Collection (ATCC), including Gram-negative bacteria (Escherichia coli ATCC 25922, Salmonella Typhimurium ATCC14028, Klebsiella pneumoniae ATCC 13883, Pseudomonas aeruginosa ATCC 9027), Gram-positive bacteria (Staphylococcus aureus ATCC 25923, Staphylococcus epidermidis ATCC 12228, Micrococcus luteus ATCC 10240, Bacillus subtilis ATCC 6633), yeast (Candida albicans ATCC 10231), and fungi Aspergillus niger, Aspergillus flavus were obtained from Microbiology Department at National Organization for Drug Control and Research. (NODCAR).

\section{Antibiotic Susceptibility Testing:}

Antibiotic susceptibility testing was performed using the Bauer-Kirby disc diffusion method by applying commercial antibiotic disc, Ciprofloxacin $(5 \mu \mathrm{g} / \mathrm{disc})$. Breakpoint criteria were established according to the Clinical and Laboratory Standards Institute (CLSI) guidelines (CLSI 2012).

\section{Antimicrobial Assay of Pomegranate Peels Extract using the Agar-Well Method:}

Pomegranate aqueous extract (PPE) was screened for their antimicrobial activity against different microorganisms using modified Kirby-Bauer disk diffusion method (Bauer et al., 1966) as follow: strains were inoculated in Mueller-Hinton broth (MHB) and Sabaurod Dextrose Agar (SDA) media then incubated at $35^{\circ} \mathrm{C}$ and $25^{\circ} \mathrm{C}$ for 24 and 48 hours for bacteria and fungi, respectively. Overnight

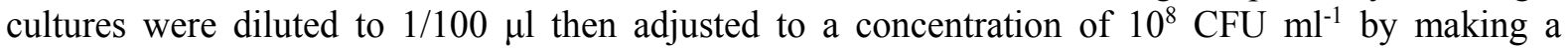
suspension in $0.85 \%$ saline solution and match with the $0.5 \mathrm{McF}$ arland turbidity standards (Hindler, and Jorgensen 1995), using a sterilized swab, aliquots from each tube were spread on Muller-Hinton agar medium, disks of Whatman filter paper soaked with aqueous extracts of $100 \mathrm{mg} / \mathrm{ml}$ were added and incubated at $35^{\circ} \mathrm{C}$ and $25^{\circ} \mathrm{C}$ for 24 and 48 hours for bacteria and fungi, respectively. Discs with water were used as a negative control and those with antibacterial and antifungal (ciprofloxacin and nystatin, respectively) used as a positive control. The experiment was tested in triplicates.

\section{Cell Culture}

Colon (Caco-2) and colorectal (HCT-116) cancer cell lines were provided by the tissue culture department (VACSERA-Egypt). Cells were cultured in RPMI 1640 medium and D-MEM supplemented with 10\% fetal bovine serum (FBS) (GIBCO, USA) and 1\% penicillin-streptomycin (Invitrogen, USA) and incubated (Jouan-France) at $37^{\circ} \mathrm{C}$ in a humidified and $5 \% \mathrm{CO}_{2}$ atmosphere.

\section{Cell Viability (MTT Assay)}

Human Caco-2 and HCT-116 cancer cells were propagated in $75 \mathrm{~cm}^{2}$ cell culture as previously mentioned according to Bussereau and Co-worker (Bussereau et al., 1982), where confluent sheet were detached using $0.25 \%(\mathrm{w} / \mathrm{v})$ trypsin solution and $0.05 \%(\mathrm{v} / \mathrm{v})$ ethylene diamine tetra-acetic acid (EDTA) (GIBCO-USA) for $5 \mathrm{~min}$. Cells were plated at a concentration of $2 \times 10^{5}$ cell $/ \mathrm{ml}$ in 96-well cell culture plates and incubated at $37^{\circ} \mathrm{C}$ for $24 \mathrm{hrs}$ to achieve confluence. The growth medium was decanted and fresh medium containing 2-fold serially diluted PPE dispensed to cells (4 wells/ dilution). Twenty-four hours later dead cells were washed out using phosphate buffered-saline (PBS) and $50 \mu \mathrm{l}$ of MTT solution $(0.5 \mathrm{mg} / \mathrm{ml})$ were added to each well. After $4 \mathrm{hrs}$. In the incubation period, the supernatants were discarded, and the formazan precipitates were solubilized by the addition of 50 $\mu \mathrm{l} /$ well of dimethyl sulfoxide (DMSO). Plates were incubated in the dark for $30 \mathrm{~min}$ at $37^{\circ} \mathrm{C}$ and absorbance was determined at a wavelength of $570 \mathrm{~nm}$ using a microplate reader (ELX -800, BioTekUSA). The cell viability percentage was calculated using the following formula: 


$$
\text { Cell viability } \%=\quad \frac{\text { Mean OD of test dilution }}{\text { OD of control well }} \times 100
$$

\section{Determination of PPE IC $\mathrm{IC}_{50}$ :}

Cytotoxicity was conducted according to Van den Berghe et al. (Van den Berghe et al., 1978), where growth medium was decanted from tissue culture Caco2 and HCT-116 cancer cell lines precultured 96 microtiter plates. PPE sample was applied as a starting concentration of $10 \mathrm{mg} / \mathrm{ml}$ in a series of 2-fold serially diluted patterns in serum-free RPMI-1640 medium and D-MEM as $0.1 \mathrm{ml}$ of each dilution/well. Negative non-treated cell control was considered. Plates were incubated at $37{ }^{\circ} \mathrm{C}$ (Jouan- France) and examined frequently for up to 3 days. Cells were checked for any toxic as partial or complete loss of monolayer, shrinkage, rounding, or cell granulation. The $\mathrm{IC}_{50}$ values were determined using Master Plex 2010 Software.

\section{Cell Cycle Analysis:}

Caco-2 and HCT-116 were pre-cultured in $25 \mathrm{~cm}^{2}$ surface area cell culture flasks were treated with the $\mathrm{IC}_{50}$ of the tested product (PPE) in RPMI-1640 medium, for $24 \mathrm{~h}$. For cell cycle analysis, the cells were harvested and fixed gently with $70 \%(\mathrm{v} / \mathrm{v})$ ethanol in PBS, maintained at a temperature of $4^{\circ} \mathrm{C}$ overnight, and re-suspended in PBS containing $40 \mu \mathrm{g} / \mathrm{ml}$ propidium iodide (PI), $0.1 \mathrm{mg} / \mathrm{ml} \mathrm{RNase}$ and $0.1 \%(\mathrm{v} / \mathrm{v})$ Triton X-100 in a dark room. After $30 \mathrm{~min}$ at $37^{\circ} \mathrm{C}$, the cells were analyzed using a flow cytometer (Becton Dickinson, San Jose, CA, USA) equipped with an argon-ion laser at a wavelength of $488 \mathrm{~nm}$. The cell cycle and sub-G1 group were determined and analyzed.

\section{Real-Time PCR: mRNA Expression of Cell Apoptosis-Related Genes:}

Total RNA was extracted from control and treated Caco-2 and HCT-116 cell lines using the Gene JET RNA Purification kit (Fermantus, UK) according to the manufacturer's protocol. The concentration and the integrity of RNA were assessed spectrophotometrically at $260 / 280 \mathrm{~nm}$ ratio. First-strand cDNA was synthesized with $1 \mu \mathrm{g}$ of total RNA using a QuantiTect Reverse Transcription kit (Qiagen, Germany) according to the manufacturer's instructions. These samples were subsequently frozen at a temperature of $-80^{\circ} \mathrm{C}$ until used for determination of the expression levels of Caspase-3, p53 and Bcl-2 genes using real-time PCR. Quantitative real-time PCR was performed on a RotorGene Q cycler (Qiagen, Germany) using QuantiTect SYBR Green PCR kits (Qiagen, Germany) and forward with reverse primers for each gene. The nucleic acid sequences of the primers were as follows CASP-3-F 5' -TTC ATT ATT CAG GCC TGC CGA GG-3' and R 5'-TTC TGA CAG GCC ATG TCA TCCTCA-3' p53 F 5'-CCCCTCCTGGCCCCTGTCATCTTC-3', R5'-GCAGCG CCTCA CAA CCTCCGTCAT-3'. Bcl-2 F 5'-CCTGTG GAT GAC TGA GTA CC-3' R 5'-GAGACA GCC AGG AGA AATCA-3' and $\beta$-actin F5'-GTGACATCCACACCCAGAGG-3' R 5'ACA GGA TGTCAAAACTGCCC-3'.

Real-time PCR mixture consisted of $12.5 \mu 12 x$ SYBR Green PCR Master Mix, $1 \mu \mathrm{L}$ of each primer $(10 \mathrm{pmol} / \mu \mathrm{l}), 2 \mu \mathrm{cDNA}$ and $8.5 \mu 1$ Rnase-free water in a total volume of $25 \mu 1$. Amplification conditions and cycle counts were a temperature of $95^{\circ} \mathrm{C}$ for $15 \mathrm{~min}$ for the initial activation, followed by 40 cycles of denaturation at $94^{\circ} \mathrm{C}$ for $15 \mathrm{~s}$, annealing at $60^{\circ} \mathrm{C}$ for the $30 \mathrm{~s}$ and elongation at $72^{\circ} \mathrm{C}$ for the 30s. Melting curves were performed after real-time PCR to demonstrate the specific cellular amplification of a single product of interest. A standard curve was performed to determine the amplification efficiency of the primers used, as well as relative fold changes in both of them.

\section{Statistical Analysis:}

All experiments were carried out in three independent tests. Data were expressed as the mean standard deviation (SD) and analyzed using a one-way analysis of variance (ANOVA). The results were considered statistically significant at $P<0.05$.

\section{Results}

\section{Identification and Quantification of Phenolic Compounds by HPLC Analysis:}

The chromatograms illustrating the phenolic compounds in the PPE are shown in Fig (1), whereas, Table (1) gives the concentrations of individual phenolic compounds identified in PPE. A 
total of 13 phenolic compounds were identified. Where, hydroxybenzoic acids such as protocatechuic acid, p-hydroxybenzoic, gallic acid, and vanillic acid, hydroxycinnamic acids such as chlorogenic, caffeic, syringic, and p-coumaric acid. Flavonoids such as rutin, Apigenin-7-glucoside, quercetin, and kaempferol were identified in PPE. The major phenolic acids are Protocatechuic $(186.37 \mathrm{ug} / \mathrm{ml})$, and p-hydroxybenzoic $(155.08 \mu \mathrm{g} / \mathrm{ml})$; While the major flavonoid is rutin $(460 \mu \mathrm{g} / \mathrm{ml})$.

Table 1: The Phenolic acids and flavonoids identified in pomegranate peel aqueous extract by HPLC.

\begin{tabular}{lc}
\hline Compound & Concentration $(\boldsymbol{\mu g} / \mathbf{m l})$ \\
\hline Gallic & 10.97 \\
Protocatechuic & 186.37 \\
$p$-hydroxybenzoic & 155.08 \\
Catechin & 4.83 \\
Chlorogenic & 6.88 \\
Caffeic & 5.33 \\
Syringic & 17.10 \\
Vanillic & 6.03 \\
p-coumaric & 6.76 \\
Rutin & 460.50 \\
Apigenin-7-glucoside & 5.36 \\
Quercetin & 2.24 \\
Kaempferol & 2.71 \\
\hline
\end{tabular}

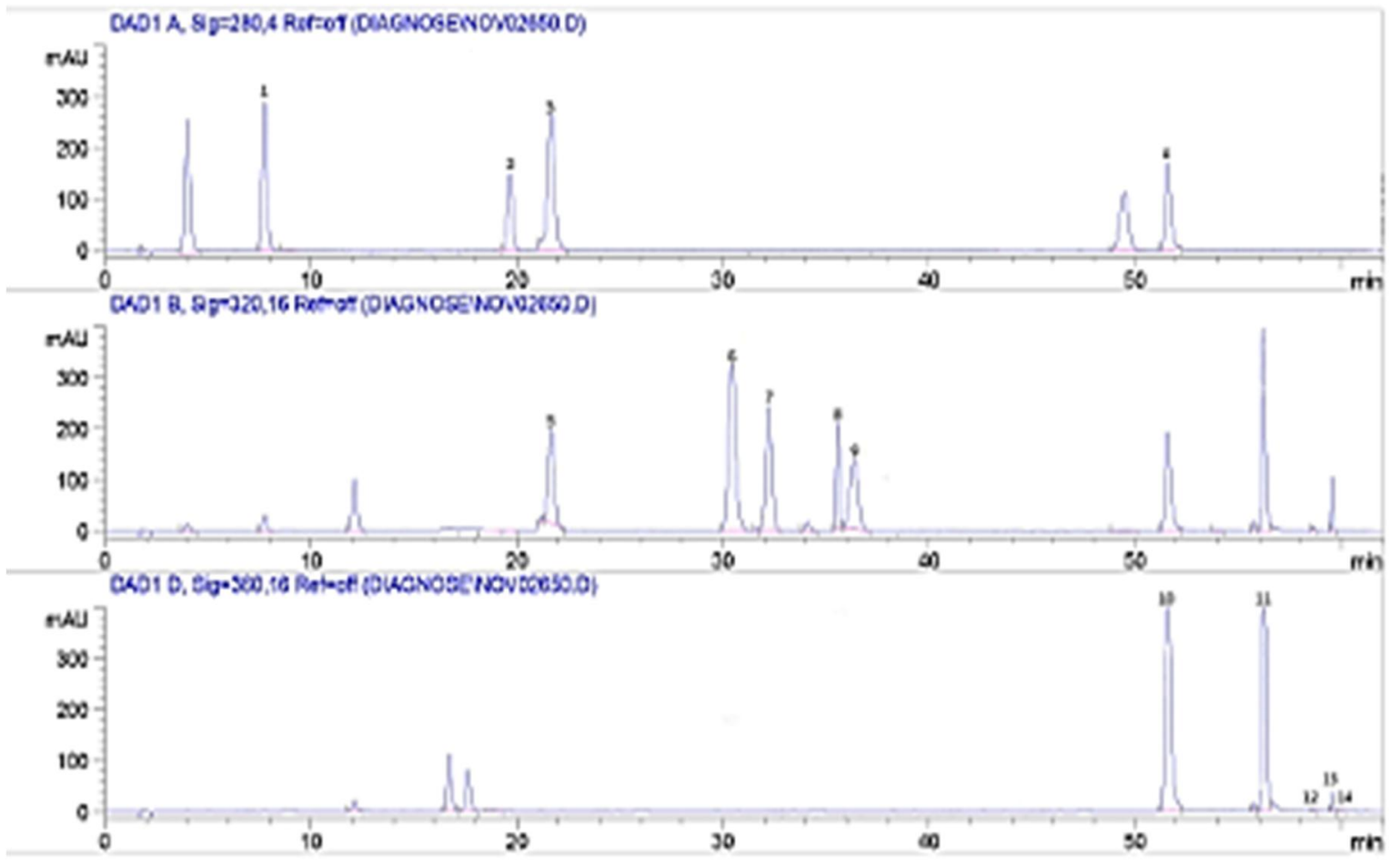

Fig. 1: Chromatogram of phenolic compounds in pomegranate aqueous extract cultivated in Egypt.Peaks:1 (Gallic acid), 2 (protocatechuic acid), 3 (catechin), 4(p-hydroxybenzoic acid), 5(vanillic acid), 6 (chlorogenic acid),7(caffeic acid), 8 (syringic acid), 9 (p-Coumaric acid), 10 (rutin),11(apigenin7-glucoside), 12(quercetin), 13 (kaempferol).

Aqueous extract of pomegranate (PPE) showed antibacterial activity against Gram-positive bacteria besides, anti-candida activity and no activity against Gram-negative bacteria was detected. The minimum inhibitory concentration of PPE was more than MIC's of standard antibiotics (Table 2). The antibacterial activity in vitro against the growth of the tested reference species of Gram-positive bacteria was shown as both concentration and species-dependent (Table 3). The tested extract had a mainly bacteriostatic effect (MBC/MIC ratio > 4) against S. aureus ATCC 25923 and M. luteus 
ATCC 10240 and bactericidal effect against both S. epidermidis ATCC 12228 and B. subtilis ATCC 6633.

Table 2: Ciprofloxacin and nystatin were used as the standard drugs for bacterial and fungal strains

\begin{tabular}{lc}
\hline Microorganism & Ciprofloxacin MIC (mg/L) \\
\hline S. aureus ATCC29213 & 0.24 \\
S. epidermidis ATCC12228 & 0.49 \\
M. luteus ATCC10240 & 0.98 \\
B. subtilis ATCC6633 & 0.03 \\
K. pneumoniae ATCC 13883 & 0.12 \\
E. coli ATCC 25922 & 0.004 \\
S. Typhimurium ATCC 14028 & 0.06 \\
P. aeruginosa ATCC 9027 & 0.49 \\
\hline Microorganism 19231 & Nystatin MIC (mg/L) \\
C. albicans ATCC10231 & 0.48 \\
Aspragillus niger & 0.24 \\
Aspragillus flavus & 0.24 \\
\hline
\end{tabular}

Table 3: Antimicrobial activity of PPE aqueous extract against test microorganisms and determination of MIC, MBC, and MFC.

\begin{tabular}{lcccc}
\hline Microorganism & $\begin{array}{c}\text { Antimicrobial activity } \\
(\mathbf{m m})\end{array}$ & $\begin{array}{c}\text { MIC } \\
(\mathbf{m g} / \mathbf{L})\end{array}$ & $\begin{array}{c}\text { MBC/MFC } \\
(\mathbf{m g} / \mathbf{L})\end{array}$ & $\begin{array}{c}\text { Ratio } \\
\text { MBC/MIC }\end{array}$ \\
\hline S. aureus ATCC 25923 & Gram-positive bacteria & & & \\
M. luteus ATCC 10240 & 25 & 15.6 & 62.5 & 4 \\
S. epidermidis ATCC 12228 & 22 & 7.8 & 31.3 & 4 \\
B. subtilis ATCC 6633 & 22.5 & 15.6 & 31.3 & 2 \\
\hline & 18.5 & 3.9 & 3.9 & 1 \\
S. Typhimurium ATCC 14028 & Gram-negative bacteria & & & \\
E. coli ATCC 25922 & No inhibition & ND & ND & ND \\
K. pneumoniae ATCC 13883 & No inhibition & ND & ND & ND \\
P. aeruginosa ATCC 27853 & No inhibition & ND & ND & ND \\
\hline & No inhibition & ND & ND & ND \\
C. albicans ATCC 10231 & Yeasts and Fungi & & & \\
Aspergillus niger & 16.0 & $>1000$ & $>1000$ & ND \\
Aspergillus flavus & No inhibition & ND & ND & ND \\
\hline & No inhibition & ND & ND & ND \\
\hline
\end{tabular}

Cytotoxicity of Pomegranate peel aqueous extract:

The cytotoxic effect of PPE was assessed by recording the various morphological changes of cells. The viability $\%$ of treated cells was cell type, extraction method, and concentration-dependent, it was found that Caco-2 was more sensitive to PPE than HCT-116 in an insignificant way $(\mathrm{P}>0.05)$. Where, $\mathrm{IC}_{50}$ of Caco-2 is 1434 and $\mathrm{IC}_{50}$ of HCT-116 is $2257 \mu \mathrm{g} / \mathrm{ml}$ [Fig.2 A, B, C].

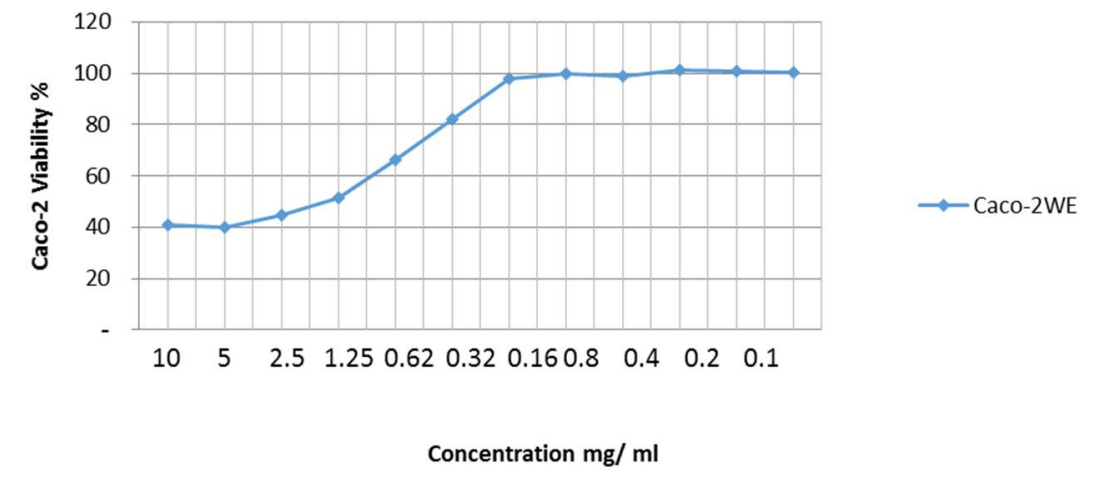

Fig. 2(A): Illustrate the correlation between the PPE concentration and the cell viability of Caco-2 


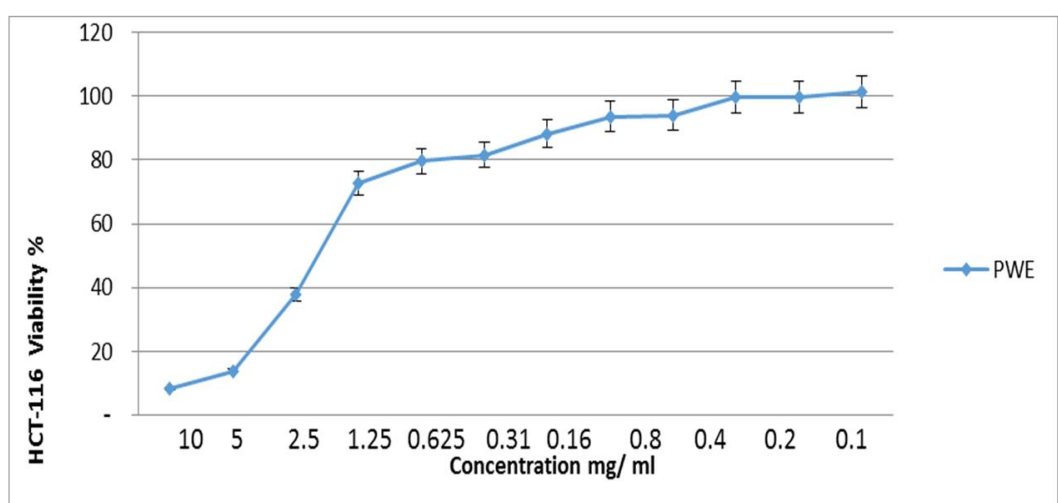

Fig. 2(B): Illustrate the correlation between the PPE concentration and the cell viability of HCT-116.

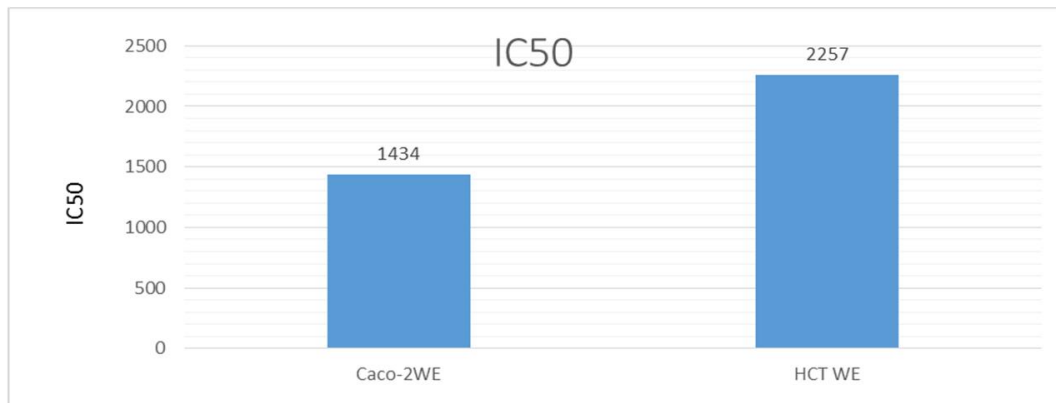

Fig. 2(C): Assessment of $\mathrm{IC}_{50}$ values of PPE post-Caco-2 and HCT-116 cancer cell lines using MTT assay (ug/ml).

\section{Cell Cycle and Apoptosis:}

Concerning the effect of PPE extract on cell cycle profile, it was noticed that Caco-2 and HCT-116 cells in the G0-G1 phase is non-significant $(\mathrm{P}>0.05)$ while, there was a significantly elevated cell accumulation during the Pre G1 and G2/M phase $(\mathrm{P}<0.05)$ compared with cell control. Also, it was noticed that cell arrest was accompanied by apoptotic profile in the pre-G1 phase in a significant way in the case of both cell lines $(\mathrm{P}<0.05)$ (Figure $3 \mathrm{~A} \& \mathrm{~B})$. The apoptotic profile accompanied by cell arrest showed that early and late apoptosis were significantly elevated in Caco-2 than in the case of HCT-116 cells $(\mathrm{P}<0.05)$ and to the values of cell control as well. Also, necrotic percentage showed the same profile (Figure $3 \mathrm{C}$ ). The anti-apoptotic activity of target extracts showed that pro-apoptotic gene (Caspase-3 and related p53) were significantly elevated post-treatment $(\mathrm{P}<0.05)$ While, the anti-apoptotic gene $(\mathrm{Bcl}-2)$ was significantly declin $((\mathrm{P}<0.05)$ compared with that in cell control as shown in (Figure 4). Finally, the biochemical changes accompanied by the apoptosis where $\mathrm{H}_{2} \mathrm{O}_{2}$ values significantly elevated $(\mathrm{P}<0.05)$, and on the other hand, catalase enzyme activity was significantly decreased as compared with cell control values $(\mathrm{P}<0.05)$, (Figure 5).
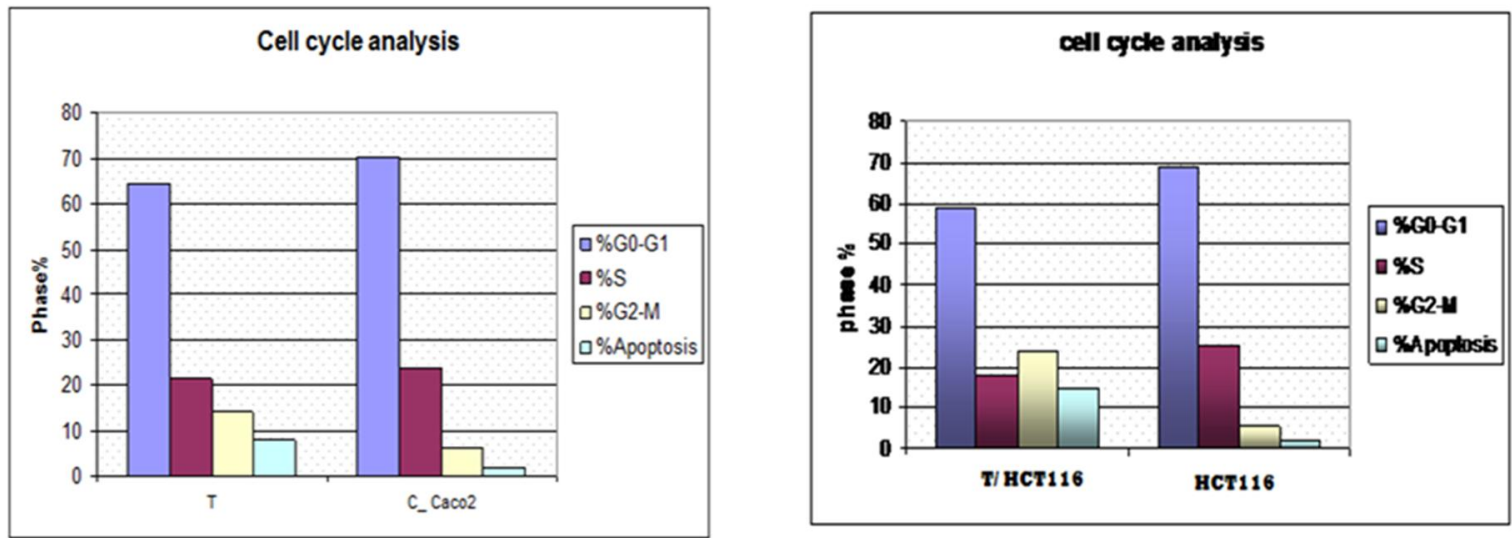

Fig. 3(A): Illustrate the cell cycle analysis and related $\%$ of arrested cells in different cell cycle phases post- treatment with PPE. 

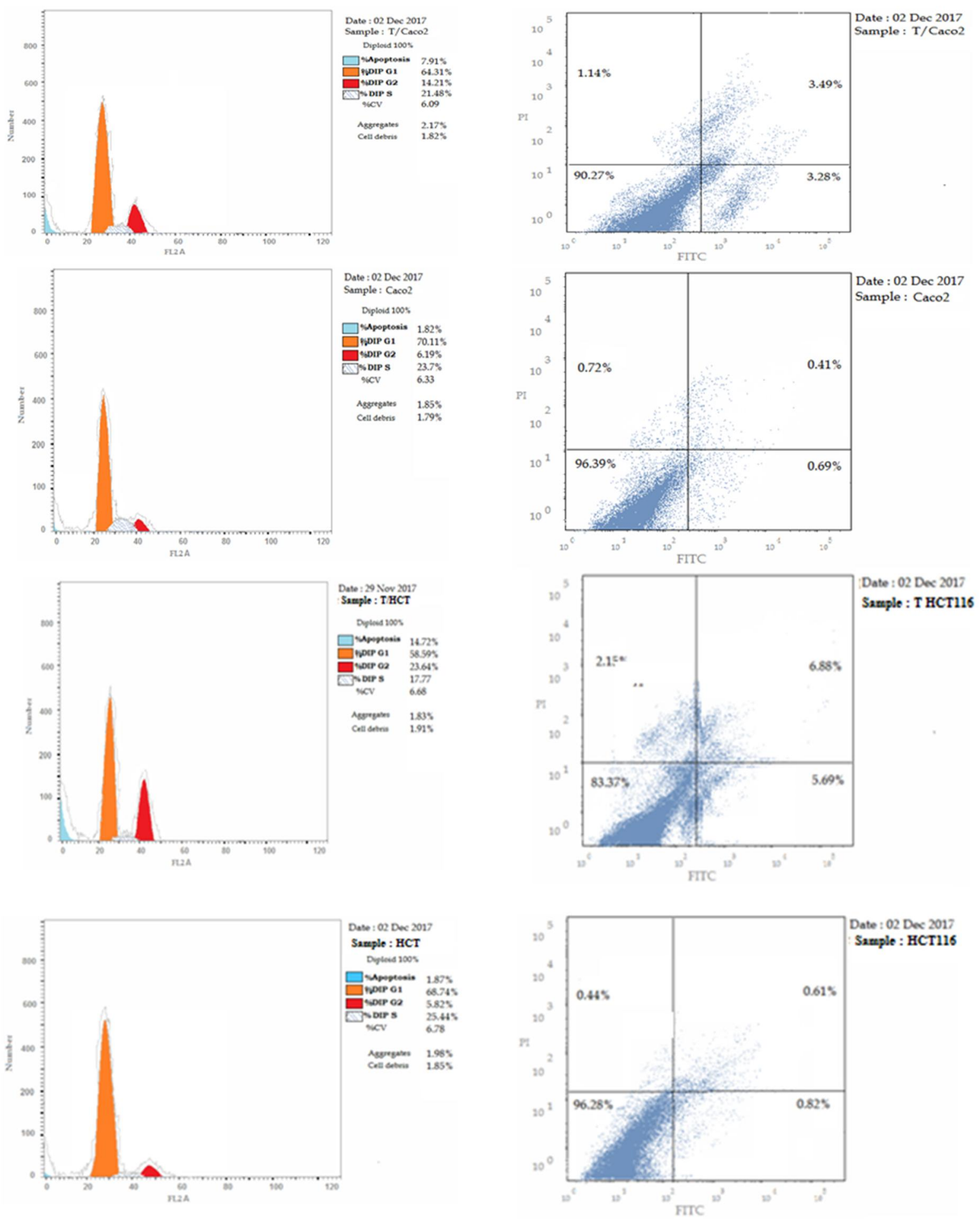

Fig. 3(B): Flow cytometric cell cycle analysis and related $\%$ of arrested cells in different cell cycle phases, as well as the apoptotic \% post-treatment with PPE using PI and Annexin V stains 


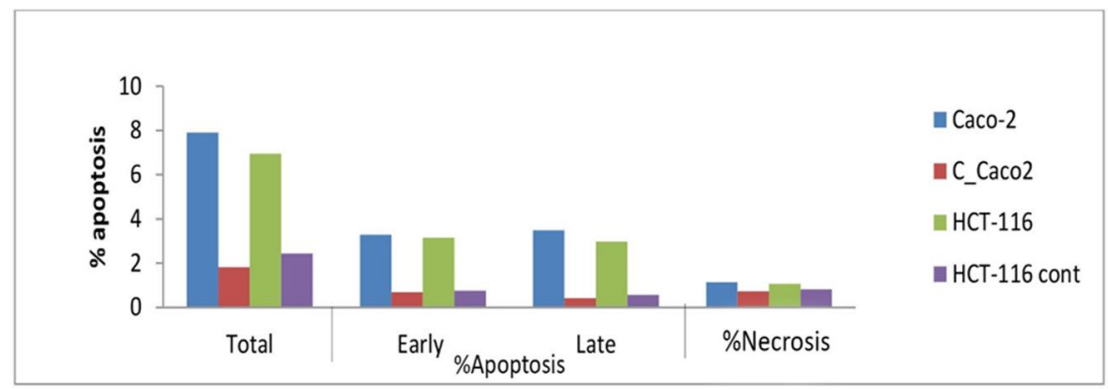

Fig. 3 (C): Apoptotic profile post- Caco-2 and HCT-116 treatment with PPE using Real-time PCR.

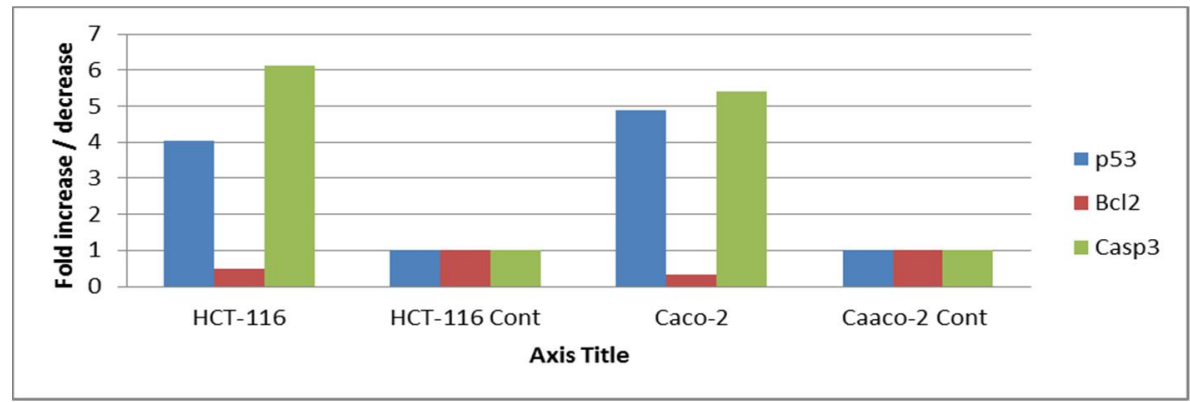

Fig. 4: Pro and anti-apoptotic gene profile post- Caco-2 and HCT-116 treatment with PPE using Real-time PCR.
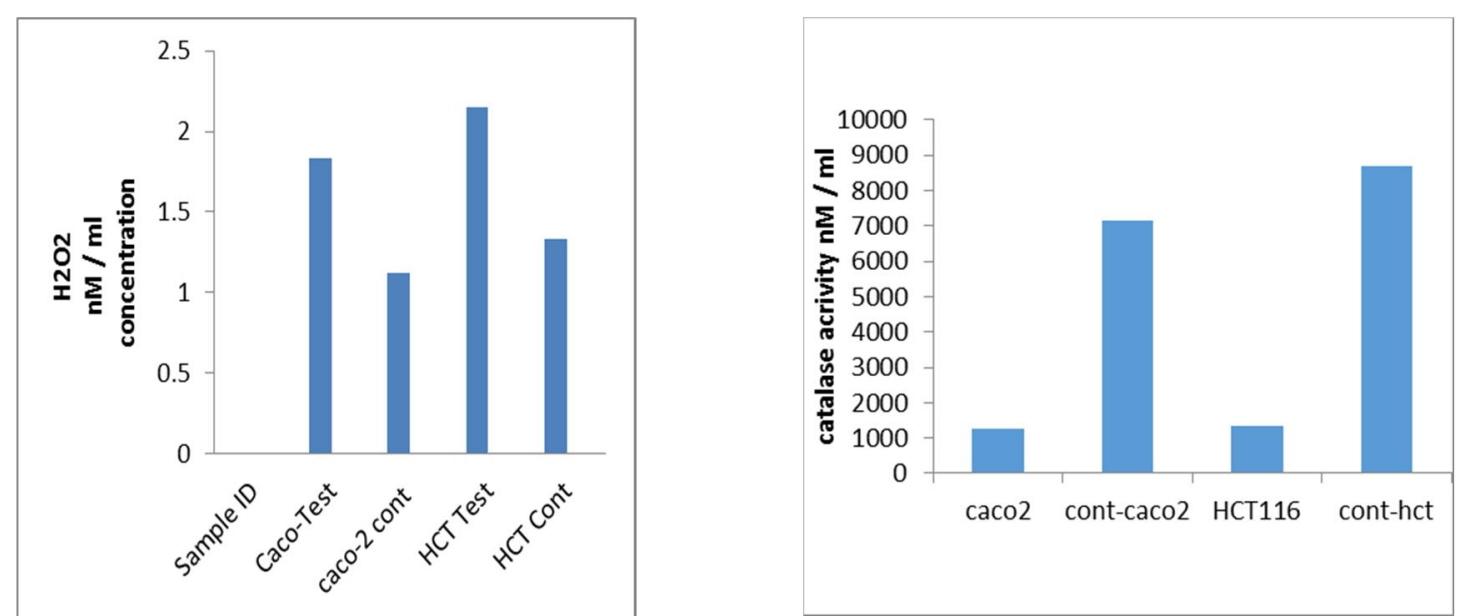

Fig. 5: Catalase and $\mathrm{H}_{2} \mathrm{O}_{2}$ activity post Caco-2 and HCT-116 treated with PPE using the biochemical assay.

\section{Discussion}

The pomegranate fruit possesses therapeutically important constituents that gained significant popularity in the treatment of many diseases. Therefore,the present study was designed to investigate the phytochemical consitituent of aqueous extract of pomegranate peel (PPE), antimicrobial and anticancer potential of PPE in human colorectal cancer (Caco-2), and colon cancer (HCT-116) cell lines. Data in our investigation revealed that PPE was cytotoxic to cancer cells in a concentration and cell type-dependent manner, where the Caco-2 cells were more sensitive to the tested extract than HCT-116. The results regarding the anti-proliferative and cytotoxic potential matched the study recorded by El-Awady et al. (2015); Shalaby et al. (2019). In the current study, to establish the PPE as a good anticancer agent, its ability to arrest the cell cycle and induce apoptosis were evaluated. According to this study, PPE caused an accumulation during the Pre G1 and G2/M phase in treated Caco-2 and HCT-116 cells. Thus, PPE caused cell cycle arrest at Pre G1 and G2/M phase. This result agrees with a previous study done in colon cancer and breast cancer cells where PPE arrested cell cycle at pre G1 and G2/M phase, respectively (Khan et al., 2007). The main purpose of cancer therapy is to target proliferating cells to induce cellular death pathways. The p53 protein is a transcription 
factor, which can induce apoptosis by regulating the pro-apoptotic and anti-apoptotic genes. The ability of p53 to promote cell death could be directly linked to its tumor- suppressive function (Schmitt et al., 2002). Bcl-2, an anti-apoptotic protein, is localized to the outer membrane of mitochondria, where it plays an important role in promoting cell survival and inhibiting the actions of pro-apoptotic proteins (Hardwick, and Soane, 2013). Bcl-2 promotor contains a p53-negative response element, raising the possibility that Bcl-2 may be a direct target of p53-mediated trans repression (Liu, 2003). p53 may also directly impact Bcl-2 activity as part of a transcriptionindependent program of cell death. In this process, cytoplasmic p53 binds to pro-apoptotic Bcl-2family proteins, leading to permeabilization of mitochondria and apoptosis (Engelbrecht et al., 2007; Ather et al., 2009). The results of the current study revealed a significant increase in p53 expersion and a significant decline in Bcl-2 in both cell lines. Caspases play an important role in maintaining homeostasis by regulating cell death and inflammation. Caspases have been broadly categorized by their known functions in apoptosis [caspase-3, -6, -7, -8 and -9 in mammals] and in inflammation [caspase-1, -4, -5 and -12 in humans] (McIlwain et al., 2013). The data obtained from the current work showed that a significant increase in the caspase -3 expression. Catalase, an antioxidant enzyme that brings about its cytoprotective action by suppressing or neutralizing the toxic hydrogen peroxide radicals produced (Sridhar et al., 2011). The results of the current work showed a significant increase in $\mathrm{H}_{2} \mathrm{O}_{2}$ and a decrease in catalase activity. The study revealed that PPE is rich in phenolic acids such as gallic acid Protocatechuic, p-hydroxybenzoic, chlorogenic acid, caffeic acid, and flavonoid like rutin where the antitumor and antibacterial activity may attribute to these compounds. This result agrees with Ross et al., (2016) who reported that anticancer properties of phenolic acids, including scavenging free radicals, induction of enzymes involved in the metabolism of xenobiotics, regulation of gene expression, modulation of cellular signaling pathways including those involved in DNA damage repair, cell proliferation, and apoptosis. The result of the current study showed that the PPE has antibacterial activity against Gram Positive-bacteria with the MIC value less than $15.6 \mathrm{mg} / 1$ and $S$. aureus recorded as the most sensitive strain. PPE extract has bactericidal activity against all tested Gram Positive-bacteria. Our data was in contract with Al-Zoreky, (2009) who reported that the aqueous extract was inactive against $S$. aureus (2 strains), B. subtilis, while agree with the finding that PPE was inactive against Gram-negative and yeasts as E. coli, Listeria monocytogenes, Pseudomonas aeruginosa, Klebsiella pneumoniae, Yersinia enterocolitica, Candida utilis, Saccharomyces cerevisiae, and Aspergillus niger. Different studies correlate the antimicrobial activity of herbal extracts to its contents of phenolic compounds, Pomegranate peel contains substantial amounts of polyphenols such as ellagic acid and gallic acids. Besides, other compounds as anthocyanins and flavonoid may act synergistically to exert their antimicrobial activity (Naz et al., 2011)

\section{Conclusion}

Pomegranate peel extract has an anti-proliferative potential against Caco-2, and HCT-116 cancer cells through induction of apoptosis proved via the up-regulation of pro-apoptotic genes; Caspase-3. As well as downregulation of anti-apoptotic genes Bcl-2. However, apoptosis induction is both dose and time-dependent manner. Also, PPE has antimicrobial activity against Gram-positive bacteria and anti-candida activity.

\section{Conflict of interest:}

The authors have no conflicts of interest to declare

$\begin{array}{ll}\text { Abbreviation: } & \\ \text { Pomegranate peel } & \text { PPE } \\ \text { Colorectal } & \text { Caco-2 } \\ \text { Colon } & \mathrm{HCT}-116 \\ \text { hydrogen peroxide } & \mathrm{H}_{2} \mathrm{O}_{2} \\ \text { Mueller-Hinton broth } & \mathrm{MHB} \\ \text { Sabaurod Dextrose Agar } & \text { SDA } \\ \text { Dimethyl sulfoxide } & \text { DMSO } \\ \text { Ethylene diamine tetra-acetic acid } & \text { EDTA } \\ \text { Death-inducing signaling complex } & \text { DISC }\end{array}$


phosphate buffered-saline

propidium iodide

fetal bovine serum
PBS

PI

FBS

\section{References}

Abdollahzadeh, S.H., R.Y. Mashouf, H. Mortazavi, M.H. Moghaddam, N. Roozbahani, and M. Vahedi, 2011. Antibacterial and antifungal activities of Punica granatum peel extracts against oral pathogens. Journal of Dentistry (Tehran, Iran), 8(1): 1-6.

Al-Zoreky, N. S., 2009. Antimicrobial activity of pomegranate (Punica granatum L.) fruit peels. International Journal of Food Microbiology, 134(3): 244-248.

Athar, M., J.H. Back, L. Kopelovich, D.R. Bickers and A.L. Kim, 2009. Multiple molecular targets of resveratrol: Anti-carcinogenic mechanisms. Archives of Biochemistry and Biophysics, 486(2), pp.95-102.

Bauer, A.W., W. M. M. Kirby, C. S. John, and T. Marvin, 1966. Antibiotic susceptibility testing by a standardized single disk method. American Journal of Clinical Pathology 45(4): 493-496.

Bussereau, F., B. Jacqueline, and S. Naima, 1982. Isolation and study of temperature-sensitive mutants of rabies virus. Journal of General Virology, 60(1): 153-158.

El-Awady, M.A., N.S. Awad, and A.E. El-Tarras, 2015. Evaluation of the anticancer activities of pomegranate (Punica granatum) and harmal (Rhazya stricta) plants grown in Saudi arabia. Int J Curr Microbiol App Sci., 4, pp.1158-1167.

Engelbrecht, A.M., M. Mary, E. Beverley, B. Loos, M. Thomas, R. Smith, S. Peters, C. Smith, and K. Myburgh, 2007. Proanthocyanidin from grape seeds inactivates the PI3-kinase/PKB pathway and induces apoptosis in a colon cancer cell line. Cancer Letters 258(1):144-153.

Faria, A. and Calhau, C., 2011. The bioactivity of pomegranate: impact on health and disease. Critical Reviews in Food Science and Nutrition, 51(7): 626-634.

Fawole, O.A., N.P. Makunga and U.L. Opara, 2012. Antibacterial, antioxidant and tyrosinaseinhibition activities of pomegranate fruit peel methanolic extract. BMC Complement Altern Med., 12:200.

Fawole, O.A., U.L. Opara, and L. Chen, 2015. Bioaccessibility of total phenolic concentration and antioxidant capacity of pomegranate fruit juice and marc after in vitro digestion. Acta Hort. 1079 (pp. 285-290).

Glazer, I., S. Masaphy, P. Marciano, I. Bar-Ilan, D. Holland, Z. Kerem, and R. Amir, , 2012. Partial identification of antifungal compounds from Punica granatum peel extracts. Journal of Agricultural and Food Chemistry, 60(19):4841-4848.

Hardwick, J.M. and L. Soane, 2013. Multiple functions of BCL-2 family proteins. Cold Spring Harbor Perspectives in Biology, 5(2), p.a008722.

Hindler, A.J. and J.H. Jorgensen, 1995. Procedures in antimicrobial susceptibility testing. MAHON, CR \& MANUSELIS Jr., G. Textbook of diagnostic Microbiology. Philadelphia, WB Saunders, pp.63-64.

Khan, N., F. Afaq, M.H. Kweon, K. Kim, and H. Mukhtar, 2007. Oral consumption of pomegranate fruit extract inhibits growth and progression of primary lung tumors in mice. Cancer Research, 67(7):3475-3482.

Liu, R. H., 2003. Health benefits of fruit and vegetables are from additive and synergistic combinations of phytochemicals. The American Journal of Clinical Nutrition 78(3): 517S-520S.

McIlwain, D.R., T. Berger, and T.W. Mak, 2013. Caspase functions in cell death and disease. Cold Spring Harbor Perspectives in Biology, 5(4):1-28.

Mphahlele, R.R., O.A. Fawole, N.P. Makunga, and U.L. Opara, 2016. Effect of drying on the bioactive compounds, antioxidant, antibacterial and antityrosinase activities of pomegranate peel. BMC Complementary and Alternative Medicine, 16(1):143-155.

Naz, S., R. Siddiqi, S. Ahmad, S. A. Rasool, and S. A. Sayeed, 2007. Antibacterial activity directed isolation of compounds from Punica granatum. Journal of food Science, 72(9): M341-M345.

Ouyang, L., Z. Shi, S. Zhao, F-T. Wang, T-T. Zhou, B. Liu and J-K. Bao, 2012. Programmed cell death pathways in cancer: a review of apoptosis, autophagy and programmed necrosis. Cell Proliferation 45(6): 487-498. 
Qabaha, K.I., 2013. Antimicrobial and free radical scavenging activities of five Palestinian medicinal plants. African Journal of Traditional, Complementary and Alternative Medicines, 10(4), pp.101108.

Rosa, L.S., N.J.A. Silva, N.C.P. Soares, M.C. Monteiro and A.J. Teodoro, 2016. Anticancer properties of phenolic acids in colon cancer-a review. J Nutr Food Sci., 6(468):10-4172.

Schmitt, C. A., S. F. Jordan, Y. Meng, B. Eugene, M. H. Robert and W. L. Scott, 2002. Dissecting p53 tumor suppressor functions in vivo. Cancer Cell, 1(3): 289-298.

Shalaby, M.T., D.H. Dawood, M. Hefni, and B.M. Murad, 2019. Phytochemical Constituents, Antimicrobial and Antitumor Effects of Pomegranate Fruit (Punica granatum L). Journal of Food and Dairy Sciences, 10(10): 373-380.

Sreekumar, S., H. Sithul, P. Muraleedharan, J.M. Azeez, and S. Sreeharshan, 2014. Pomegranate fruit as a rich source of biologically active compounds. BioMed Research International, 2014:1-12

Sridhar, T.M., D. Preethi, and C.V. Naidu, 2011. Effect of silver thiosulphate on In Vitro plant regeneration of Solanum nigrum (Linn.) An important antiulcer medicinal plant. Current Botany, 2(7):14-16.

Van den Berghe, P.L., 1978. Race and ethnicity: a sociobiological perspective. Ethnic and Racial Studies, 1(4): 401-411.

Wayne, P. A., 2012. Performance Standards for Antimicrobial Susceptibility Testing: Twenty-Second informational Supplement. Clinical and Laboratory Standards Institute, M100-S22. USA. 